\title{
Residue of Select Organochlorine Pesticides (OCPs) in Sediment from Vietnam's CauBay River and Their Impact on Agricultural Soil and Human Health
}

\author{
Vu Duc Toan* \\ Vietnam Water Resources University, 175 Tay Son Street, Hanoi, Vietnam \\ Received: 24 June 2014 \\ Accepted: 3 September 2014
}

\begin{abstract}
An evaluation of OCP residue (OCPs $=\alpha, \beta, \delta, \gamma-\mathrm{HCH}$ isomers, $p, p$ '-DDE, $p, p$ '-DDD, $p, p$ '-DDT) from the CauBay River and the KieuKy area in Vietnam was carried out. The CauBay has played an important role in irrigated water supply for agriculture activities in KieuKy downstream. The OCP concentrations of sediment and soil samples were analyzed and results indicated the wide extent of contamination of OCPs in the CauBay (DDTs: $68.35 \pm 13.57 \mathrm{ng} \cdot \mathrm{g}^{-1} \mathrm{dw}$; HCHs: $7.82 \pm 2.36 \mathrm{ng} \cdot \mathrm{g}^{-1} \mathrm{dw}$ ) and KieuKy (DDTs: $85.24 \pm 15.43 \mathrm{ng} \cdot \mathrm{g}^{-1}$ $\mathrm{dw}$; HCHs: $6.94 \pm 1.49 \mathrm{ng} \cdot \mathrm{g}^{-1} \mathrm{dw}$ ). This clearly reflected the effects of OCP residue from the CauBay on quality of KieuKy agricultural soil. The OCP composition analyses in the samples reflect their long-time release. The total cancer risk of OCPs in KieuKy soil fell into a very low range, suggesting low risk. However, since OCPs were the species of POPs with more concern in this area, ecological risk assessment should be further investigated.
\end{abstract}

Keywords: organochlorine pesticides, sediment, residue, human health risk

\section{Introduction}

Of all organochlorine pesticides with a high potential environmental and human health impact, dichlorodiphenyl trichloroethane (DDTs) and hexachloro cyclohexane $(\mathrm{HCHs})$ have received the most attention in Vietnam. They have been used in the country in considerable amounts as pesticides for crop protection and as vector control for public health purposes. Concern about the toxicology of these compounds has led to governmental efforts to control their use and disposal.

From the viewpoint of these selected OCP contaminants $\left(\mathrm{OCPs}=\alpha, \beta, \delta, \gamma\right.$-HCH isomers, $p, p^{\prime}-\mathrm{DDE}, p, p^{\prime}-$

\footnotetext{
*e-mail: vuductoan@wru.edu.vn vuductoan2001@yahoo.com
}

DDD, $p, p^{\prime}$-DDT), their residue can be found in several places in Vietnam are found, such as QuangTri, Bacning, Hue, and Hanoi [1]. However, there is a lack of studies that discuss OCP transportation from place to place by the rivers. OCPs can be evaporated and transported in the atmospheric by "global cold condensation effect" but in our opinion, rivers is also one of their important dispersions into the environment. OCP residues in sediment can be transported along the rivers and have significant impacts in the downstream.

Hanoi, the capital of Vietnam, is the center of the economy for the whole country. The CauBay River is a very important channel to discharge various wastewaters from households and industries in Hanoi being upstream from the LongBien District and downstream from the KieuKy area. The CauBay also is the only source to supply irrigat- 
ed water to that area. Possible OCP sources from the CauBay will seriously affect the soil quality of KieuKy. However, to our knowledge a little data are available for the contamination of OCPs in this river as well as the impact of OCP residues on agricultural soil and human health risk in the downstream. The objectives of this research are to assess the levels and distributions of OCPs in the surficial sediments from the CauBay River and in the agricultural soil of the KieuKy area to fill this gap.

\section{Experimental Procedures}

The sampling was carried out in April 2014. Ten sediment samples in 10 sites along the CauBay and 10 soil samples in KieuKy were collected. The sampling locations were chosen at random, with an attempt to get them evenly distributed over the selected region (Fig. 1). The samples were taken with solvent-rinsed stainless steel scoops from the upper $5 \mathrm{~cm}$ of the soil and then transferred to pre-cleaned polyethylene bags. The surficial sediment was collected with a stainless steel grab $(0-20 \mathrm{~cm})$. The collected samples were homogenized, air dried at room temperature $\left(22-25^{\circ} \mathrm{C}\right)$, ground, and sieved through a steel mesh (1 $\mathrm{mm}$ grid size). All samples were maintained at $4^{\circ} \mathrm{C}$ until analysis. The equipment used for sample collection, transportation, and preparation were free from OCP contamination.

The analytical procedure of select OCP residues in collected samples was as follows. First, a $10 \mathrm{~g}$ sample was extracted for 30 min with ultrasonication using $60 \mathrm{~mL}$ dichloromethane-acetone $(1: 1 \mathrm{v} / \mathrm{v})$ two times. The two extracts were combined and the activated copper was added to remove element sulfate and then dehydrated with anhydrous sodium sulfate. The extracts were concentrated to about $1-2 \mathrm{~mL}$ by a rotary evaporator, and further purified with a glass column (12 $\mathrm{mm}$ i.d.) loaded with $10 \mathrm{~g}$ activated Florisil (60-100 mesh, Supelco Chemical Co., Germany). The elution was subsequently carried out using $10 \mathrm{ml}$ hexane containing $10 \%$ acetone $(\mathrm{v} / \mathrm{v})$. The effluents were concentrated to $0.1 \mathrm{~mL}$ under a gentle stream of pure nitrogen for GC analysis. The samples were analyzed with a gas chromatograph (Varian Star 3400Cx) equipped with DB5 column $(30 \mathrm{~m}$ length $\times 0.32$ i.d. $\mathrm{mm} \times 0.25 \mu \mathrm{m}$ film thickness) and mass spectrophotometer (Varian Saturn 2000). The residue levels of DDT and HCH were determined by the external standard method using peak areas. The standard mixture containing $\alpha, \beta, \delta, \gamma-\mathrm{HCH}$ isomers, $p, p$ '-DDE, $p, p$ '-DDD, and $p, p$ '-DDT with a concentration of $200 \mathrm{ng} \cdot \mu^{-1}$ per compound was purchased from Supelco Chemical Co., Germany.

DDTs were determined as the sum of $p, p^{\prime}-\mathrm{DDE}, p, p^{\prime}-$ DDD and $p, p$ '-DDT, whereas HCHs was determined as the sum of $\alpha, \beta, \gamma$ and $\delta$ isomers. The method detection limits of the select OCPs were calculated from real samples as 3 times the signal/noise ratio and were $0.02 \mathrm{ng} \cdot \mathrm{g}^{-1}$ dry weights (dw) for $p, p$ '-DDT, $p, p^{\prime}-\mathrm{DDD}$, and $p, p^{\prime}$-DDE, $0.05 \mathrm{ng} \cdot \mathrm{g}^{-1}$ $\mathrm{dw}$ for $\alpha-\mathrm{HCH}, \beta-\mathrm{HCH}, \gamma-\mathrm{HCH}$, and $\delta-\mathrm{HCH}$. One procedural blank was run for every set of five samples to check for secondary contamination. The recoveries of $\alpha-\mathrm{HCH}, \beta$ $\mathrm{HCH}, \gamma-\mathrm{HCH}, \delta-\mathrm{HCH}, p, p$-DDE, $p, p^{\prime}-\mathrm{DDD}$ and $p, p$ 'DDT with spiked CauBay samples ranged from 82 to $98 \%$. Duplicates of samples were also performed and relative standard deviations were less than $15 \%$. All concentrations were calculated with respect to the dry weight of samples. Total organic carbon (TOC) of samples was analyzed using a TOC analyzer (TOC-VCPH, Shimadzu Corp., Japan).

Methods to estimate the OCP cancer risks via ingestion, dermal contact, and inhalation of soil particles in the KieuKy area were developed by the U.S. Environmental Protection Agency [2, 3].

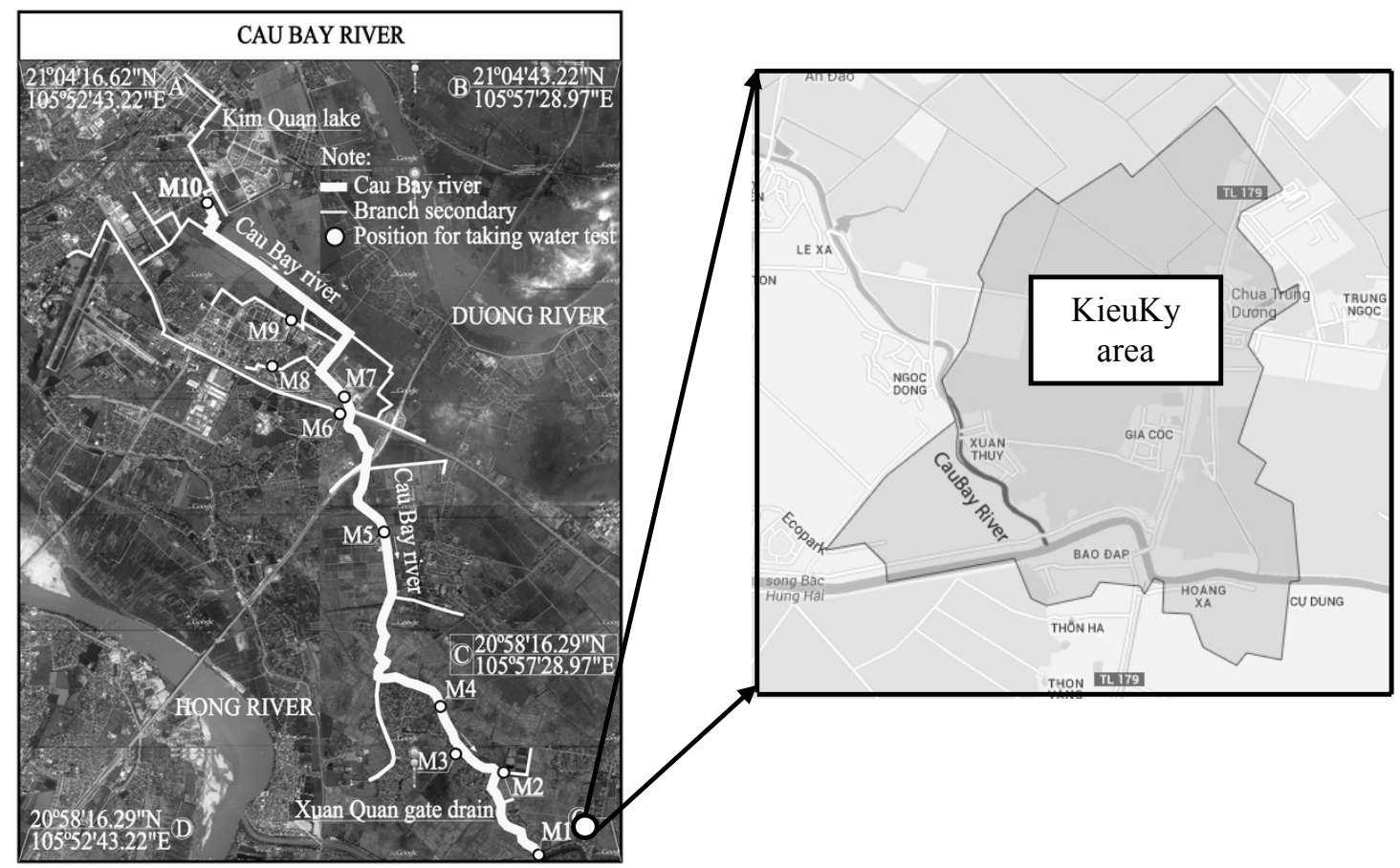

Fig. 1. Study area and sampling locations. 
Table 1. OCPs concentrations ( $\left.\mathrm{ng} \cdot \mathrm{g}^{-1}\right)$ and TOC (\%) in the sediment samples from the CauBay River.

\begin{tabular}{|c|c|c|c|c|}
\hline Compound & Minimum & Maximum & Mean & Standard Deviation \\
\hline$\alpha-\mathrm{HCH}$ & 1.73 & 4.22 & 3.08 & 0.92 \\
\hline$\beta-\mathrm{HCH}$ & 2.04 & 4.82 & 3.35 & 0.98 \\
\hline$\gamma-\mathrm{HCH}$ & 0.43 & 1.39 & 0.83 & 0.32 \\
\hline$\delta-\mathrm{HCH}$ & 0.16 & 1.19 & 0.55 & 0.36 \\
\hline $\mathrm{HCHs}^{(\mathrm{a})}$ & 4.48 & 11.32 & 7.82 & 2.36 \\
\hline$p, p^{\prime}-\mathrm{DDE}$ & 30.59 & 45.49 & 36.84 & 5.48 \\
\hline$p, p^{\prime}-\mathrm{DDD}$ & 13.59 & 23.89 & 17.66 & 3.32 \\
\hline$p, p^{\prime}$-DDT & 4.72 & 20.39 & 13.85 & 5.32 \\
\hline DDTs $^{(b)}$ & 48.82 & 89.76 & 68.35 & 13.57 \\
\hline TOC & 2.31 & 4.21 & 3.18 & 0.66 \\
\hline
\end{tabular}

${ }^{(a)} \mathrm{HCH}$ is sum of $\alpha, \beta, \gamma, \delta$-HCH; ${ }^{\left({ }^{(b)}\right.} \mathrm{DDTs}$ is sum of $p, p^{\prime}$-DDT, $p, p^{\prime}$-DDE, $p, p^{\prime}$-DDD.

\section{Discussion of Results}

The select OCP concentrations in the CauBay sediment samples are all shown in Table 1. OCPs were detected in all samples.

The DDT concentrations ranged from 48.82 to 89.76 $\mathrm{ng} \cdot \mathrm{g}^{-1}$ with a mean $68.35 \pm 13.57 \mathrm{ng} \cdot \mathrm{g}^{-1} \mathrm{dw}$. The results point out the common usage of DDT as pesticides for crop protection near the CauBay river. Because the use of technical DDT in Vietnam was banned in 1992, this clearly indicates that the residues of DDT are a result of the use of such compounds over the last decades. It also might be a results of technical DDT used as a vector control for public health purposes in Hanoi.

With regards to $\mathrm{HCHs}$, low concentrations were detected in the analyzed sediment samples. The HCH concentrations ranged from 4.48 to $11.32 \mathrm{ng} \cdot \mathrm{g}^{-1}$ (mean $7.82 \pm 2.36$ $\mathrm{ng} \cdot \mathrm{g}^{-1} \mathrm{dw}$ ). Similar to DDTs, the contamination of HCHs originated in the use as pesticides for crop protection and as vector control for public health purposes. $\mathrm{HCHs}$ were also probably deposited into the urban areas by atmospheric transport from agricultural areas. From the sediment, $\mathrm{HCHs}$ may be accumulated in aquatic animals and then in the human body. Therefore, although their concentrations were low, the presence of HCHs in all sediment samples is clearly marked. The analyzed data in Table 1 clearly shows that the concentrations of HCHs in CauBay sediments displayed uniform low distribution. Contrary to the results of $\mathrm{HCHs}$, the distributions of medium level contamination of DDTs from CauBay were displayed.

When compared with other regions in the world, the CauBay DDT concentrations are comparable with those in some estuaries of China, northern KwaZulu-Natal, South Africa, and lower than the northeastern coast of India [4-6]. Meanwhile, the CauBay $\mathrm{HCH}$ concentrations are lower than those in sediments of the northeastern coast of India, and higher than residues found in Xiaman Harbour, China $[4,6]$.
The kinetic behavior of hydrophobic organic pollutants can be influenced by organic carbon contents in sediment. Our study shows that the concentrations of DDTs and $\mathrm{HCHs}$ in CauBay sediments are correlated at weak positive level with TOC contents. The Pearson correlations between TOC and DDT concentrations, TOC and HCH concentrations are 0.49 and 0.52 , respectively.

Besides the contamination status of select OCPs, the analysis of their composition is useful to understand their patterns as well as possible contaminant sources. The order of mean percentages of DDT and its metabolites in sediment samples from CauBay was $p, p^{\prime}-\mathrm{DDE}(54.5 \%)>p, p^{\prime}-$ DDD $(25.9 \%)>p$, $p$ '-DDT $(19.6 \%)$. DDT can be biodegraded in the environment to DDD under anaerobic conditions and to DDE under aerobic conditions. With regards to DDT metabolites, the ratio of ( $p, p^{\prime}-\mathrm{DDE}+p, p^{\prime}-$ DDD) $/ \Sigma D D T$ in the sediment samples from CauBay ranged between 0.77 and 0.90 (mean 0.80 ). This indicates that the degradation of DDT occurred significantly and there is no recent input of DDT in the study areas.

Technical $\mathrm{HCH}$ and lindane $(>99 \% \gamma-\mathrm{HCH})$ have been officially banned since 1994 in Vietnam. The mean percentages of $\mathrm{HCH}$ isomers in analyzed CauBay sediment samples followed the order $\beta-\mathrm{HCH}(43.4 \%)>\alpha-\mathrm{HCH}$ $(39.4 \%)>\gamma-\mathrm{HCH}(10.5 \%)>\delta$-HCH $(6.7 \%)$. Among the isomers, $\beta-\mathrm{HCH}$ has the lowest water solubility and vapour pressure. It is the most stable isomer and is relatively resistant to microbial degradation. Besides that, there is the isomerization of $\alpha$ - to $\beta-\mathrm{HCH}$ and of $\gamma$ - via $\alpha$ - to the more stable $\beta-\mathrm{HCH}$, which is energetically more favourable in the environment. Therefore, the predominance of $\beta-\mathrm{HCH}$ reflects an old source of input of $\mathrm{HCH}$ in the environment. Low ratios of $\alpha-\mathrm{HCH} / \gamma-\mathrm{HCH}$ may represent the use of lindane, whereas high ratios of these isomers may depict the use of technical $\mathrm{HCH}$. The ratio of $\alpha-\mathrm{HCH} / \gamma-\mathrm{HCH}$ in areas where lindane has been typically used ranges from 0.2 to 1 , compared to a range of 4-15 for technical $\mathrm{HCH}$. Here, the ratios of $\alpha-\mathrm{HCH} / \gamma-\mathrm{HCH}$ in the analyzed CauBay sediment 
Table 2. OCP concentrations (ng $\left.\cdot \mathrm{g}^{-1}\right)$ in KieuKy soil samples.

\begin{tabular}{|c|c|c|c|c|}
\hline Compound & Minimum & Maximum & Mean & Standard Deviation \\
\hline$\alpha-\mathrm{HCH}$ & 1.68 & 3.98 & 2.62 & 0.72 \\
\hline$\beta-\mathrm{HCH}$ & 2.35 & 4.19 & 3.09 & 0.68 \\
\hline$\gamma$-HCH & 0.56 & 0.97 & 0.76 & 0.16 \\
\hline$\delta$-HCH & 0.15 & 0.69 & 6.94 & 1.49 \\
\hline HCHs & 5.56 & 9.77 & 43.72 & 7.52 \\
\hline$p, p^{\prime}-\mathrm{DDE}$ & 32.86 & 50.92 & 22.05 & 3.94 \\
\hline$p, p^{\prime}-\mathrm{DDD}$ & 15.43 & 25.97 & 19.47 & 4.16 \\
\hline$p, p^{\prime}-\mathrm{DDT}$ & 12.09 & 23.49 & 85.24 & 15.43 \\
\hline DDTs & 62.27 & 98.66 & & \\
\hline
\end{tabular}

samples range from 2.7 to 4.2 (mean 3.8). This result confirmed the use of technical $\mathrm{HCH}$ as a major source and lindane as the minor source in the study areas.

The risk assessment was carried out based on the standard of Canadian Environmental Quality Guideline for freshwater sediments [7]. Accordingly, criteria such as the interim sediment quality guideline (ISQG) and the probable effect level (PEL) for $\mathrm{HCH}$ and DDT compounds were compared with their respective concentrations in CauBay sediments. Compared to the criteria for DDE, DDD, DDT, $\gamma$-HCH (ISQG: 1.42, 3.54, 1.19, 0.94; PEL: 6.75, 8.51, 4.77, $1.38 \mathrm{in} \mathrm{ng} / \mathrm{g} \mathrm{dw}$, respectively), all sediment samples in the present study exceed the ISQG and PEL values for DDT and its metabolism. With regards to $\gamma-\mathrm{HCH}$, all sediment samples were below PEL value, whereas $40 \%$ of samples exceed the ISQG values. This result indicated medium risk of select OCPs in the CauBay sediment.

Besides accumulating in sediment, OCPs can be redistributed from sediment to water and be transported along the CauBay River. OCPs can penetrate the irrigated water and accumulate in the agricultural soil downstream. To assess this situation, agricultural KieuKy soil samples that have direct contact with irrigated CauBay water were analyzed and OCPs were detected in all representative samples (Table 2).

The DDT and $\mathrm{HCH}$ concentrations in agricultural soil samples ranged from 62.27 to $98.66 \mathrm{ng} \cdot \mathrm{g}^{-1} \mathrm{dw}$ (mean $85.24 \pm 15.43 \mathrm{ng} \cdot \mathrm{g}^{-1} \mathrm{dw}$ ), and from 5.56 to $9.77 \mathrm{ng} \cdot \mathrm{g}^{-1} \mathrm{dw}$ (mean $6.94 \pm 1.49 \mathrm{ng} \cdot \mathrm{g}^{-1} \mathrm{dw}$ ), respectively. The obtained results clearly show the impact of OCP residues from the CauBay sediment on the quality of KieuKy agricultural soil. OCP residue in soil samples from KieuKy are comparable with those in soil of the Central Tibetan Plateau, China and lower than those in soil samples of Bacninh Province, Vietnam, [1,8].

Human risk assessment was evaluated via inhalation of soil particles, dermal contact, and ingestion. According to the Human Health Evaluation Manual, the OCP cancer risk in agricultural soil can be calculated by using Eq. (1-3) [2, 3].

$$
\begin{gathered}
C R_{\text {ingest }}=\frac{C_{\text {soil }} \times \operatorname{IngR} \times E F \times E D \times C F \times S F_{\text {oral }}}{B W \times A T} \\
\frac{C R_{\text {dermal }}=}{B W \times A T} \times S A \times A F_{\text {soil }} \times A B S \times E F \times E D \times C F \times S F_{\text {oral }} \times G I A B S \\
C R_{\text {inhale }}=\frac{C_{\text {soil }} \times I n h R \times E F \times E D \times I U R \times A F_{\text {Inh }}}{P E F \times A T}
\end{gathered}
$$

...where: $C R_{\text {ingest }}$ is the cancer risk $(C R)$ via accidental ingestion of soil; $C R_{\text {dermal }}$ is the cancer risk via dermal contact of soil; $C R_{\text {inhale }}$ is the cancer risk via inhalation of soil; $C_{\text {soil }}$ is the concentration of the OCPs in soil $\left(\mathrm{mg} \cdot \mathrm{kg}^{-1}\right)$. The meaning of other parameters in these equations and their selected values of input parameters are listed in Table 3.

OCP CR via exposure pathways are calculated using selected values of input parameters (Table 3) and levels of OCP concentrations in KieuKy soil samples. As shown in Table 4, the calculated total cancer risks for DDTs and $\mathrm{HCHs}$ of all sampling locations range from 3.96E-07 to $6.28 \mathrm{E}-07$ and from $4.0 \mathrm{E}-07$ to $6.3 \mathrm{E}-07$, respectively. According to the Human Health Evaluation Manual [3], the following qualitative ranking of cancer risk estimates was used to rank the risk from very low to very high: very low (value $\left.\leq 10^{-6}\right)$; low $\left(10^{-6}<\right.$ value $\left.\leq 10^{-4}\right)$; moderate $\left(10^{-4}<\right.$ value $\left.\leq 10^{-3}\right)$; high $\left(10^{-3} \leq\right.$ value $\left.<10^{-1}\right)$; and very high (value $\left.\geq 10^{-1}\right)$. Thus, the obtained total CR is at the very low cancer risks rank. For different exposure pathways, the increasing trend in risks of cancer for OCPs was as follows: inhalation $<$ dermal contact $<$ ingestion. Since OCPs were the species of POPs with more concern in this area, ecological risk assessment should be further investigated.

\section{Conclusions}

Wide occurrence of OCP residue was found from CauBay River sediment. It is observed that high OCP values corresponded with the sites near wastewater discharge from industrial areas along the CauBay. All sediment sam- 
Table 3. Selected values of input parameters to calculate CR for DDTs and HCHs.

\begin{tabular}{|c|c|c|}
\hline Symbol & Meaning of parameters & Selected values \\
\hline IngR & Soil ingestion rate $\left(\mathrm{mg} \cdot \mathrm{days}^{-1}\right)$ & 100 \\
\hline ED & Exposure duration (years) & 70 \\
\hline $\mathrm{EF}$ & Assumed exposure frequency (days/year) & 350 \\
\hline $\mathrm{CF}$ & Conversion factor $\left(\mathrm{kg} \cdot \mathrm{mg}^{-1}\right)$ & $1 \times 10^{-6}$ \\
\hline $\mathrm{SF}_{\text {oral }}$ & Oral slope factor $\left(\mathrm{mg} \cdot \mathrm{kg}^{-1} \cdot \mathrm{days}^{-1}\right)^{-1}$ & $2.0 \mathrm{E}+00$ \\
\hline AT & Upper-bound value of averaging time (days) & $70 \times 365=25,550$ \\
\hline BW & Average body weight (kg) & 70 \\
\hline SA & Contact surface area of skin with soil $\left(\mathrm{cm}^{2}\right)$ & 3,300 \\
\hline $\mathrm{AF}_{\text {soil }}$ & Skin adherence factor for soil $\left(\mathrm{mg} \cdot \mathrm{cm}^{2}\right)$ & $0.2 \mathrm{mg} \cdot \mathrm{cm}^{2}$ \\
\hline ABS & Dermal absorption factor $(\%)$ & $\begin{array}{c}0.2 \text { (for DDTs) * } \\
0.1 \text { (for } \mathrm{HCHs} \text { ) }\end{array}$ \\
\hline GIABS & Fraction of contaminant absorbed in gastrointestinal tract & 1 \\
\hline $\mathrm{AF}_{\text {Inh }}$ & Absorption factor for the lungs & 1 \\
\hline $\operatorname{InhR}$ & Inhalation rate $\left(\mathrm{m}^{3} \cdot\right.$ days $\left.^{-1}\right)$ & 15.8 (for adults) \\
\hline $\mathrm{SF}_{\text {oral }}$ & Oral slope factor $\left(\mathrm{mg} \cdot \mathrm{kg}^{-1} \cdot \mathrm{days}^{-1}\right)^{-1}$ & $2.0 \mathrm{E}+00$ \\
\hline PEF & Particle emission factor $\left(\mathrm{m}^{3} \cdot \mathrm{kg}^{-1}\right)$ & $1.36 \times 10^{9}$ \\
\hline IUR & Inhalation unit risk $\left(\mathrm{mg} \cdot \mathrm{m}^{3}\right)^{-1}$ & $(5.7 \mathrm{E}-01)$ \\
\hline
\end{tabular}

*Data from Health Canada [9].

Table 4. OCP CR via exposure pathways.

\begin{tabular}{|l|c|c|c|}
\hline \multicolumn{1}{|c|}{$\begin{array}{c}\text { OCPs CR via } \\
\text { exposure pathways }\end{array}$} & Minimum & Maximum & Mean \\
\hline \multicolumn{4}{|c|}{ DDTs } \\
\hline Ingestion & $1.71 \mathrm{E}-07$ & $2.68 \mathrm{E}-07$ & $2.34 \mathrm{E}-07$ \\
\hline Dermal contact & $2.25 \mathrm{E}-07$ & $3.57 \mathrm{E}-07$ & $3.08 \mathrm{E}-07$ \\
\hline Inhalation & $3.95 \mathrm{E}-10$ & $6.26 \mathrm{E}-10$ & $5.41 \mathrm{E}-10$ \\
\hline Total CR & $3.96 \mathrm{E}-07$ & $6.28 \mathrm{E}-07$ & $5.42 \mathrm{E}-07$ \\
\hline & HCHs \\
\hline Ingestion & $1.7 \mathrm{E}-07$ & $2.7 \mathrm{E}-07$ & $2.3 \mathrm{E}-07$ \\
\hline Dermal contact & $2.3 \mathrm{E}-07$ & $3.6 \mathrm{E}-07$ & $3.1 \mathrm{E}-07$ \\
\hline Inhalation & $4.0 \mathrm{E}-10$ & $6.3 \mathrm{E}-10$ & $5.4 \mathrm{E}-10$ \\
\hline Total CR & $4.0 \mathrm{E}-07$ & $6.3 \mathrm{E}-07$ & $5.4 \mathrm{E}-07$ \\
\hline
\end{tabular}

ples in the present study exceeded the ISQG and PEL values for DDT and its metabolism. With regards to $\gamma-\mathrm{HCH}$, all sediment samples were below PEL value whereas $40 \%$ of samples exceeded the ISQG values. This result indicated medium risk of OCPs in the CauBay sediment. The quality of KieuKy agricultural soil downstream has been clearly affected by OCP residues in CauBay sediment. The OCP composition analyses in the samples reflect their long-time release. The total cancer risk of OCPs in the KieuKy soil fell into a very low range, suggesting low risk.

\section{Acknowledgements}

This research is funded by the Vietnam National Foundation for Science and Technology Development (NAFOSTED) under grant No. 105.09-2012.09. The author would also like to thank Vietnam Water Resources University for its support.

\section{References}

1. TOAN V.D., THAO V.D., WALDER J., SCHMUTZ HANS-RUDOLF., HA C.H. Temporal Trend and Half-Life Time of Selected Organochlorine Pesticides (OCPs) in Surface Soils from Bacninh, Vietnam. B. Environ. Contam. Tox. 82, 516, 2009.

2. USEPA. Exposure factors handbook. EPA/600/P-95/002F, Environmental Protection Agency, Washington, 1997.

3. USEPA. Risk assessment guidance for superfund, Vol. I: human health evaluation manual (F, supplemental guidance for inhalation risk assessment) EPA/540/R/070/002 Environmental Protection Agency, Washington, 2009.

4. HONG S.H., KIM U.H., SHIM W.J., OH J.R., VIET P.H., PARK P.S. Persistent organochlorine residues in estuarine and marine sediments from Ha Long Bay, Hai Phong Bay, and Ba Lat Estuary, Vietnam. Chemosphere 72, 1193, 2008.

5. HUMPHRIES S.M. DDT residue contamination in sediments from Lake Sibaya in northern KwaZulu-Natal, South Africa: Implications for conservation in a World Heritage Site. Chemosphere, 93, (8), 1494, 2013.

6. MISHRA K., SHARMA C.R., KUMAR S. Contamination profile of DDT and $\mathrm{HCH}$ in surface sediments and their spa- 
tial distribution from North-East India. Ecotox. Environ. Safe. 95, 113, 2013.

7. CCME (Canadian Council of Minister of the Environment). Canadian quality guidelines for the protection of aquatic life: Summary table: Canadian environmental quality guideline, Winnipeg, Manitoba), 2014.

8. YUAN L-G., QIN J-X., LI J., LANG X-X., WAN G-H. Persistent organic pollutants in soil near the
Changwengluozha glacier of the Central Tibetan Plateau, China: Their sorption to clays and implication. Sci. Total Environ. 472, 309, 2014.

9. Health Canada. Federal Contaminated Site Risk Assessment in Canada, Part I: Guidance on Human Health Preliminary Quantitative Risk Assessment (PQRA), Environmental Health Assessment Services, Safe Environments Directorate, 2004. 